Original Research

\title{
Implant failure in bilateral metal-on-metal hip resurfacing arthroplasties: a clinical and pathological study
}

\author{
Yoshinubo Uchihara ${ }^{1} \cdot$ George Grammatopoulos ${ }^{2} \cdot$ Mitsuru Munemoto $^{1} \cdot$ Gulraj Matharu $^{2} \cdot$ Yusuke Inagaki $^{1}$. \\ Hemant Pandit ${ }^{2} \cdot$ Yasuhito Tanaka ${ }^{1} \cdot$ Nick A. Athanasou ${ }^{2}$
}

Received: 10 December 2017 / Accepted: 22 February 2018 / Published online: 7 March 2018

(c) Springer Science+Business Media, LLC, part of Springer Nature 2018

\begin{abstract}
Metal-on-metal hip resurfacing arthroplasties (MoMHRAs) have a high failure rate due to pseudotumour formation. It is not certain whether pseudotumours in bilateral MoMHRAs form on the basis of an adverse reaction to metal debris (ARMD) that is entirely due to a local innate and adaptive immune response to Cobalt-Chrome $(\mathrm{Co}-\mathrm{Cr})$ wear particles. To determine if there is a systemic component to ARMD in bilateral MoMHRAs, we examined the histology of ARMD in unilateral and bilateral MoMHRAs revised for pseudotumour and determined whether implant survival differed between these two groups. Periprosthetic tissue specimens from 119 hips revised for pseudotumour were examined. These were derived from 109 patients including 10 patients with bilateral MoMHRAs and 99 with sunilateral MoMHRAs including a cohort of 20 patients with bilateral MoMHRAs that had undergone only one MoMHRA revision for pseudotumour. The mean time to revision for pseudotumour of unilateral and bilateral MoMHRAs was determined. The histology of periprosthetic tissue was examined for evidence of the innate and adaptive immune response and scored semi-quantitatively. There was no significant difference in histological features of the innate / adaptive response between Group 1 bilateral pseudotumours and Group 2 and Group 3 unilateral pseudotumours. Histological features, including ALVAL scores, were similar in the periprosthetic tissues of right and left hips in Group 1 bilateral MoMHRAs. The mean time to first revision for pseudotumour of bilateral MoMHRAs (6.59 years) was not decreased compared with unilateral MoMHRAs (5.66 years) or bilateral MoMHRAs that had only one revision (7.05 years). Right and left hip pseudotumours in bilateral MoMHRAs exhibit similar histological features of the innate and adaptive immune response. Mean implant survival is not decreased in bilateral compared with unilateral MoMHRA cases. The findings suggest that pseudotumour formation is due more to a local than a systemic innate /adaptive immune response to components of metal wear.
\end{abstract}

George Grammatopoulos

george.grammatopoulos@ndorms.ox.ac.uk

Nick A. Athanasou

nick.athanasou@ndorms.ox.ac.uk
1 Department of Orthopaedic Surgery, Nara Medical University, Shijocho 840, Kashihara, Nara 634-8522, Japan

2 Nuffield Department of Orthopaedics, Rheumatology and Surgery, Nuffield Orthopaedic Centre, University of Oxford, Headington, Oxford OX3 7HE, UK 


\section{Graphical Abstract}

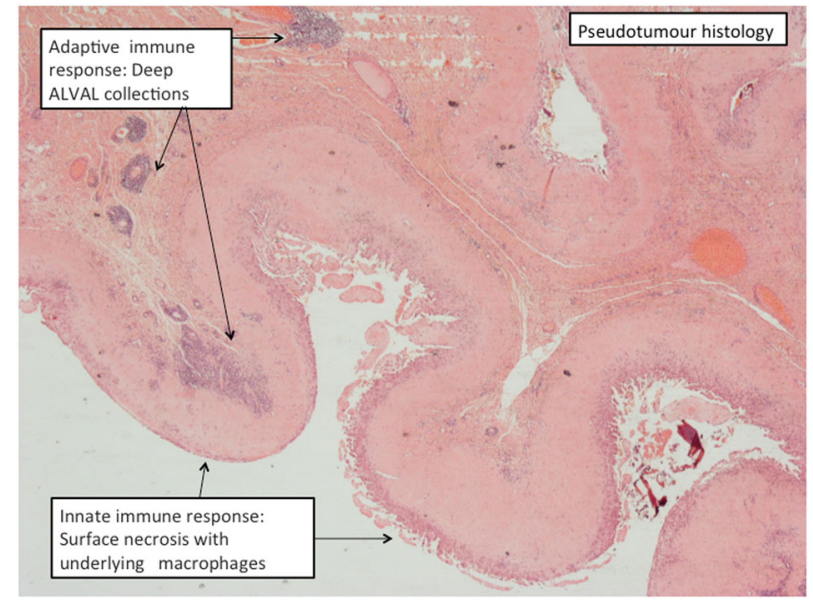

\section{Introduction}

Metal-on-metal (MoM) hip resurfacing arthroplasties (MoMHRAs) have been associated with an unacceptably high early/mid-term failure rate due to an adverse reaction to metal debris (ARMD) [1-3]. Hip MoM implants produce large amounts of nanometre-sized cobalt-chrome (Co-Cr) wear particles and induce both an innate and adaptive immune response to components of metal wear [4]. The innate response is characterised by an infiltrate of foreign body macrophages that phagocytose $\mathrm{Co}-\mathrm{Cr}$ wear particles; these particles are cytotoxic and can lead to macrophage apoptosis and tissue necrosis. The adaptive immune response is characterized by a focally heavy lymphocyte and plasma cell infiltrate with collections of lymphoid cells around vessels, a feature which has been termed "aseptic lymphocyte-dominated vasculitis-associated lesion" (ALVAL) [5]. Both the innate and adaptive immune response contribute to ARMD and pseudotumour formation, the most common cause of MoMHRA failure [6, 7].

Bilateral hip joint arthroplasty, carried out as a one-stage, or more commonly as a two-stage procedure, is sometimes undertaken for patients who suffer from bilateral arthritic conditions. A number of studies have shown that in bilateral metal on polyethylene (MoP) arthroplasties carried out for osteoarthritis and other arthritic conditions, outcomes are similar to unilateral MoP arthroplasties in terms of implant survival and other complications [8-10]. Hip MoM implants, including MoMHRAs, have also been used to treat bilateral hip arthritis [11-14]. Increased metal ion levels have been correlated in some studies with the development of ARMD and serum metal ion levels are higher in patients with bilateral compared with unilateral
MoMHRAs [14-17]. In a previous study, we reported pathological findings in a small series of patients with bilateral MoMHRAs that developed bilateral pseudotumours [18]. Evidence of both an innate and adaptive immune response was noted in the periprosthetic tissues of both hip implants and it was hypothesized that a systemic innate and adaptive response to components of metal wear may have played a role in pseudotumour formation.

To determine if there is a systemic component to the development of pseudotumours in bilateral MoMHRAs, we have reviewed histological findings in a large number of bilateral and unilateral MoMHRA cases revised for pseudotumour. The degree of the innate and adaptive immune response in these cases was assessed by determining the extent of the foreign body macrophage and lymphocyte/ plasma cell (i.e., ALVAL) response respectively in periprosthetic tissues. We correlated our results with implant survival in order to examine not only whether there is a systemic component to pseudotumour formation in bilateral MoMHRAs but also whether there is a difference in outcome between bilateral and unilateral MoMHRAs.

\section{Materials and methods}

\subsection{Patient and implant data}

One hundred and nineteen hips from 109 patients were analysed. The cases were divided into three groups: -

Group 1 comprised 20 hips from 10 patients who had revision of failed bilateral MoMHRAs for pseudotumour. Patient and implant details from this cohort are shown in Table 1. 
Table 1 Bilateral MoMHRA patients, implant details and histological findings in pseudotumours

\begin{tabular}{|c|c|c|c|c|c|c|c|c|c|c|}
\hline Case no. & Sex & Right/Left & Age at op. & Implant & Head size & Cup size & Diagnosis & Implant duration & ALVAL grade & Macrophage grade \\
\hline 1 & $\mathrm{~F}$ & $\mathrm{~L}$ & 42.18 & Conserve & 46 & 52 & Primary OA & 6.64 & $1+$ & $3+$ \\
\hline 1 & $\mathrm{~F}$ & $\mathrm{R}$ & 43.77 & Conserve & 46 & 52 & Primary OA & 5.52 & $1+$ & $2+$ \\
\hline 2 & $\mathrm{~F}$ & $\mathrm{~L}$ & 52.77 & Recap & 44 & 50 & Primary OA & 5.68 & $3+$ & $3+$ \\
\hline 2 & $\mathrm{~F}$ & $\mathrm{R}$ & 54.27 & Recap & 44 & 50 & Primary OA & 3.70 & $3+$ & $3+$ \\
\hline 3 & $\mathrm{~F}$ & $\mathrm{~L}$ & 45.98 & Conserve & 40 & 46 & Perthes & 5.06 & $3+$ & $2+$ \\
\hline 3 & $\mathrm{~F}$ & $\mathrm{~L}$ & 47.05 & Conserve & 42 & 48 & Primary OA & 6.41 & $3+$ & $3+$ \\
\hline 4 & M & $\mathrm{L}$ & 52.48 & BHR & 50 & 56 & Primary OA & 8.31 & $3+$ & $3+$ \\
\hline 4 & M & $\mathrm{R}$ & 52.48 & BHR & 50 & 56 & Primary OA & 12.05 & $3+$ & $3+$ \\
\hline 5 & $\mathrm{~F}$ & $\mathrm{R}$ & 48.00 & BHR & 50 & 56 & Primary OA & 5.44 & $3+$ & $2+$ \\
\hline 5 & $\mathrm{~F}$ & $\mathrm{~L}$ & 48.36 & BHR & 50 & 56 & Primary OA & 7.61 & $3+$ & $3+$ \\
\hline 6 & $\mathrm{~F}$ & $\mathrm{R}$ & 49.45 & BHR & 46 & 52 & Primary OA & 9.11 & $3+$ & $3+$ \\
\hline 6 & $\mathrm{~F}$ & $\mathrm{~L}$ & 50.16 & BHR & 46 & 52 & Primary OA & 8.40 & $3+$ & $2+$ \\
\hline 7 & $\mathrm{~F}$ & $\mathrm{R}$ & 64.68 & BHR & 50 & 56 & Primary OA & 2.12 & $3+$ & $2+$ \\
\hline 7 & $\mathrm{~F}$ & $\mathrm{~L}$ & 64.90 & BHR & 50 & 56 & Primary OA & 0.79 & $3+$ & $2+$ \\
\hline 8 & $\mathrm{~F}$ & $\mathrm{R}$ & 54.79 & BHR & 46 & 52 & Primary OA & 10.45 & $3+$ & $3+$ \\
\hline 8 & $\mathrm{~F}$ & $\mathrm{~L}$ & 54.95 & BHR & 46 & 52 & Primary OA & 11.54 & $3+$ & $3+$ \\
\hline 9 & $\mathrm{~F}$ & $\mathrm{R}$ & 49.62 & BHR & 50 & 56 & Primary OA & 8.94 & $3+$ & $2+$ \\
\hline 9 & $\mathrm{~F}$ & $\mathrm{~L}$ & 57.08 & BHR & 54 & 56 & Primary OA & 1.80 & $3+$ & $3+$ \\
\hline 10 & M & $\mathrm{L}$ & 57.60 & BHR & 46 & 52 & Primary OA & 6.45 & $2+$ & $3+$ \\
\hline 10 & M & $\mathrm{R}$ & 59.01 & Conserve & 46 & 52 & Primary OA & 5.69 & $2+$ & $3+$ \\
\hline
\end{tabular}

Group 2 comprised 79 hips from patients who had revision of a failed unilateral MoMHRA for pseudotumour. The implants were: Conserve (Conserve $^{\circledR}$ Plus Total Resurfacing Hip System, Wright Medical Technology, Arington, TN, USA), in 37 cases; BHR (Birmingham Hip Resurfacing System, Smith \& Nephew, Memphis, Tennessee, USA) in 32 cases; Recap (Recap ${ }^{\circledR}$ Femoral Resurfacing system, Biomet, Warsaw, Indiana, USA) in 8 cases and Cormet (Cormet $2000^{\mathrm{TM}}$, Corin, Lincester, UK) in 2 cases.

Group 3 comprised 20 patients with bilateral MoMHRAs who had undergone revision for unilateral MoMHRA failure due to pseudotumour. In these cases, no evidence of a pseudotumour on the contralateral side was identified on clinical assessment or cross-sectional imagining (see below). The implants were Conserve in 6 cases, BHR in 12 cases, Recap in 1 case and Cormet in 1 case.

Groups 2 and 3 were derived from a recent single-centre prospective cohort study of 1429 MoMHRAs (1216 patients, 40\% female) implanted between 1999 and 2009 [10], All cases had radiological evidence of a pseudotumour on the basis of MRI, CT or ultrasound investigations. None of the cases in Groups 1, 2 or 3 was revised for infection and in all cases the index operation was carried out for primary osteoarthritis.

\subsection{Histopathological analysis}

The specimens submitted included capsule/synovium, femoral and acetabular membrane and pseudotumour. The mean number of specimens submitted from each case was six (range 2-13). None of the specimens had histological or microbiological evidence of infection.

As a measure of the innate immune response, the extent of the foreign body macrophage infiltrate in MoM periprosthetic tissues was assessed in haematoxylin-eosinstained $5 \mu \mathrm{m}$ tissue sections by histological analysis as previously described [19]. The extent of macrophage infiltrate was as $1+$ (few), $2+$ (many), or $3+$ (abundant) and an assessment of necrosis also noted. The ALVAL response was graded using the Oxford ALVAL scoring system whereby: $0=$ no evidence of a perivascular lymphoid infiltrate; $1=$ little evidence of perivascular lymphoid infiltrate with lymphocyte cuffing of blood vessels being fewer than 5 cells in thickness; $2=$ several perivascular lymphoid aggregates with lymphocyte cuffing of vessels being five to ten cells in thickness; $3=$ numerous large perivascular lymphoid aggregates with lymphocyte cuffing around vessels being more than ten cells in thickness [20]. As inflammatory changes are not uniform in periprosthetic tissues, the ALVAL score was based on the maximum perivascular lymphoid infiltrate noted in any one specimen. 
At least twenty fields per specimen (100x magnification) were examined. The N-1 chi-square test was used to compare histological findings between the two groups.

\section{Results}

\subsection{Implant survival in bilateral and unilateral MoMHRAs}

The mean time to first revision for the 20 pseudotumours in the bilateral MoMHRA cases was 6.59 years (standard deviation $=3.08$ years; range $0.79-12.1$ years; median $=$ 6.43 years; IQR 3.70-9.11 years). The mean time to revision for pseudotumour in 79 unilateral MoMHRA revisions for pseudotumour was 5.66 years (standard deviation 3.06 years; range $0.70-2.5$ years; median $=5.65$ years; IQR 1.10-10.1 years). In a further 20 bilateral MoMHRA cases where only one of the MoMHRA had been revised for pseudotumour, the mean time to revision of the MoMHRA's for pseudotumour was 7.04 years (standard deviation $=2.84$ years; range $0.9-12.3$ years; median $=7.05$ years; $\mathrm{IQR}=3.70-10.9$ years).

\subsection{Histological findings}

It was noted that similar histological features of ARMD were present in periprosthetic tissues of pseudotumours in both the right and left hips in (Group 1) bilateral MoMHRA cases. Reflecting the innate immune response, a significant $(2+/ 3+)$ macrophage response to wear particles was noted in all cases; this was accompanied by extensive cell/tissue necrosis, mainly on the surface of pseudotumours (Fig. 1). A few scattered foreign body macrophage polykaryons were noted in some specimens but these were not commonly seen in either bilateral (or unilateral) MoMHRAs. Evidence of an adaptive immune response with a diffuse, focally heavy lymphoid infiltrate that included lymphocytes, plasma cells and perivascular lymphoid aggregates (i.e., ALVAL) was seen in all Group 1 pseudotumours with $80 \%$ of bilateral MoMHRA cases having a high (Grade 3) Oxford ALVAL score in both right and left hips (Table 1; Fig. 2). In one case the Oxford ALVAL score was Grade 1 in both hips and, in another case, the Oxford ALVAL score was Grade 2 in both hips. Group 2 (unilateral MoMHRA with one revised pseudotumour) and Group 3 (bilateral MoMHRAs with one revised pseudotumour) also showed a prominent macrophage infiltrate $(2+/ 3+)$ and cell/tissue necrosis in periprosthetic tissues. In Group 2 cases, the Oxford ALVAL score was Grade 3 in $76 \%$ with 17.6 and 6.3\% Grade 2 and Grade 1 respectively. In Group 3 cases, the Oxford ALVAL score was Grade 3 in $70 \%$ with 20 and 10\% Grade 2 and Grade 1 respectively. There was no
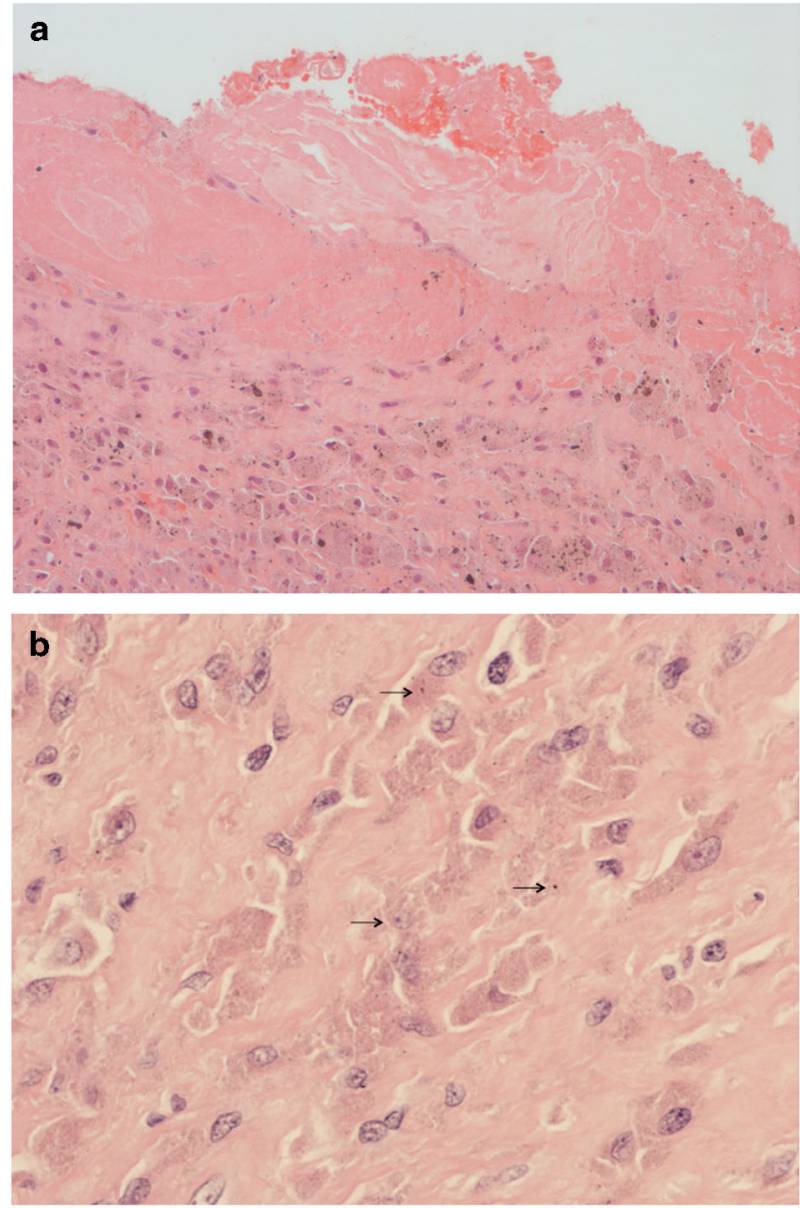

Fig. 1 Histological features of the innate immune response in a pseudotumour showing: a surface tissue necrosis with underlying infiltrate of macrophages conataining metal wear particles $\mathbf{b}$ macrophages containing granular metal wear particles including some black particulate aggregates (some arrowed)

statistically significant difference in ALVAL scores between the two groups.

\section{Discussion}

National Joint Registry data indicate that MoM hip implants, including MoMHRAs, have higher short/midterm failure rates compared with non-MoM articulations [2, 3]. Revision arthroplasty for MoMHRA failure is most commonly carried out because of development of a pseudotumour as a consequence of ARMD [7]. In this study, we show that bilateral MoMHRAs revised for pseudotumour exhibit similar pathological features of an innate and adaptive immune response in both hips and that implant survival in bilateral MoMHRAs is not decreased compared with unilateral MoMHRAs which also exhibit features of ARMD. 

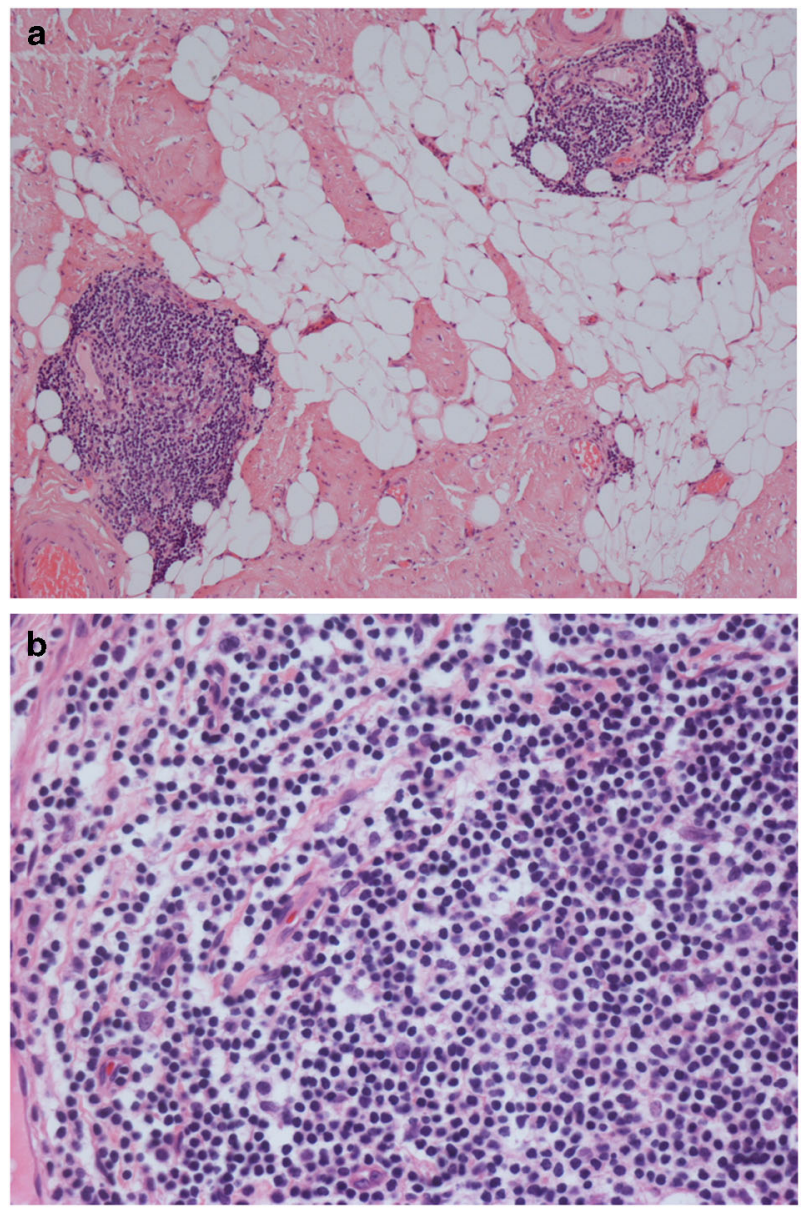

Fig. 2 Right hip pseudotumour (Case 4) showing: a two (Oxford Grade 2/3) ALVAL collections in capsular fat and fibrous tissue. b High-power view showing numerous lymphocytes in one of the ALVAL collections

The pathology of ARMD occurs as a consequence of the innate and adaptive immune response to components of metal wear [4]. The innate immune response is effectively a non-specific foreign body macrophage response to the very large number of nanometer-size Co-Cr particles generated from MoM implants. These particles are coated with host proteins derived from blood and interstitial fluid and, following phagocytosis of the metal protein complex, transported to intracellular lysosomes where they undergo corrosion, resulting in the release of $\mathrm{Co}$ and $\mathrm{Cr}$ ions. The cytotoxic effect of metal ions on macrophages, fibroblasts and other cells in periprosthetic tissues is well recognised and results in the marked tissue necrosis seen in ARMD [21-23]. In patients with bilateral MoMHRAs, it is known that there are high levels of metal ions in the circulation [14-16]. Co and $\mathrm{Cr}$ ions have been detected in extraarticular tissues remote from the implant site where they have been shown to cause tissue damage [24]. Whether elevated serum metal ion levels correlate with an increase in implant failure due to ARMD is controversial [20, 25-27].
In vitro studies have shown that high levels of Co significantly decrease the viability of macrophages that have phagocytosed metal wear particles [28, 29]. Increased numbers of pseudotumours have been noted in patients with bilateral compared unilateral MoM total hip replacements, with higher blood metal ion levels being seen in bilateral pseudotumour cases [30]. Although the results of these investigations suggest that high blood metal ion levels in patients with bilateral MoMHRAs may have an effect on the innate immune response that leads to pseudotumour formation, we noted a significant $(2+/ 3+)$ macrophage infiltrate and necrosis in periprosthetic tissues in both bilateral and unilateral MoMHRA cases, suggesting no major additive effect in this regard.

The pathology of ARMD in periprosthetic tissues is also often marked by a pronounced, perivascular lymphocyte and plasma cell reaction termed ALVAL [4, 5]. This lymphoid response is thought to develop as a result of an adaptive cell-mediated Type IV reaction to $\mathrm{Co}-\mathrm{Cr}$ wear particles, or, more specifically, cell and tissue components altered by interaction with $\mathrm{Co}-\mathrm{Cr}$ wear particles [4, 23]. Co$\mathrm{Cr}$ particles produce high levels of metal ions that act as haptens which combine with large carrier (cell-or tissuederived) protein molecules that may become immunogenic, resulting in a cell-mediated hypersensitivity response. When pseudotumours associated with bilateral MoMHRAs were first reported, concerns were raised that the ARMD response in the second MoMHRA may have resulted from prior sensitization to metal wear from the first MoMHRA in a manner analogous to the Type IV metal hypersensitivity reaction seen in contact dermatitis [18]. We noted that the Oxford ALVAL score in peri-implant tissues of both right and left MoM hips was similar in bilateral MoMHRAs. In one case, a low Oxford ALVAL score (Grade 1) was seen in both MoMHRAs peri-implant tissues, suggesting that there was no additive effect from prior sensitization to metal wear; similarly, in another case, the ALVAL score was Grade 2 in both hips. In all other cases, the Oxford ALVAL score was high (Grade 3), indicating that there was a pronounced adaptive immune response to metal wear particles in both hips. Madanat et al in an MRI study also noted symmetry of adverse local tissue reactions in patients with bilateral simultaneous and sequential MoMHRAs [31]. As noted previously [27], we found that most unilateral MoMHRA cases have a high (Grade 3) Oxford ALVAL score. Unilateral MoMHRAs and bilateral MoMHRA cases with revision of only one MoMHRA also showed no significant difference in the ALVAL response histologically.

It has been stated that patients with bilateral MoMHRAs have a higher risk of developing ARMD [32]. Our results show, however, that implant survival in unilateral and bilateral MoMHRAs revised for pseudotumours is not markedly different. In fact, implant survival was slightly 
higher in bilateral compared with unilateral MoMHRAs, including cases that had bilateral MoMHRAs where only one implant had been revised for pseudotumour. Implant survival has not been shown to be significantly different in bilateral hip replacements using other forms of articulation such as MoP [8-10]. The absence of a difference in implant survival between unilateral and bilateral MoMHRAs, coupled with our histological findings that there is no significant difference in the innate and adaptive immune response between unilateral and bilateral MoMHRAs, suggests that higher metal ion levels and prior sensitization to metal wear components in bilateral MoMHRAs does not appear to significantly influence pseudotumour formation. Our study has several limitations, including the absence of measurement of $\mathrm{Co}$ and $\mathrm{Cr}$ levels in the cases studied and the use of archival data in a retrospective study involving different implant types. In addition, our histological findings were restricted to identifying the main cell types involved in the innate and adaptive immune response to components of metal wear in periprosthetic tissues ie foreign body macrophages and lymphocytes/plasma cells respectively [4-6]; we did not assess the role of other inflammatory cells (eg dendritic cells, natural killer cells, eosinophils) and humoral factors (e.g., interleukins, tumour necrosis factor, interferon-gamma) that are known to play a role in innate and adaptive immunity [33-35]. However, our findings would indicate that ARMD and pseudotumour formation occur principally as a result of a local rather than systemic reaction to components of metal wear.

Acknowledgements The authors thank Sarah Turton for typing the manuscript.

Author contributions NAA and HP have provided expert opinion in implant-related medicolegal cases.

\section{Compliance with ethical standards}

Conflict of interest The authors declare that they have no conflict of interest.

\section{References}

1. Jones LC, Haggard WO, Greenwald AS. Overview of metal-onmetal implants. In: Jones LC, Greenwald S, Haggard WO, editors. Metal on metal bearings: a clinical practicum. London: Springer; 2014. p. 3-11.

2. NJR Editorial Board National Joint Registry 2015. www. njrcentre.org.uk.

3. Australian Orthopeadic Association National Joint Registry Annual Report, 2016. Hip and Knee Arthroplasty. www.apa.org. au.

4. Athanasou NA. The pathobiology and pathology of aseptic implant failure. Bone Jt Res. 2016;5:162-8.

5. Willert HG, Buchhorn GH, Fayyazi A, Flury R, Windler M, Koster G, Lohmann CH. Metal-on-metal bearings and hypersensitivity in patients with artificial hip joints. A clinical and histomorphological study. J Bone Jt Surg Am. 2005;87A:28-36.

6. Pandit H, Glyn-Jones S, McLardy-Smith P, Gundle R, Whitwell D, Gibbons CL, Ostlere S, Athanasou N, Gill HS, Murray DW. Pseudotumours associated with metal-on-metal hip resurfacings. J Bone Jt Surg. 2008;90B:847-51.

7. Matharu GS, Judge A, Murray DW, Pandit HG. Prelevance and risk factors for hip resurfacing revision: a cohort study into the second decade after the operation. J Bone Jt Surg Am. 2016;98A:1444-52.

8. Kim YH. Bilateral cemented and cementless total hip arthroplasty. J Arthroplast. 2002;17:434-40.

9. Stavrakis AI, SooHoo NF, Lieberman JR. Bilateral total hip arthroplasty has similar complication rates to unilateral total hip arthroplasty. J Arthroplast. 2015;7:1211-4.

10. Lampropoulou-Adamidou K, Macheras GA, Hartofilakidis G. Bilateral character of total hip replacement does not change the overall survival. Hip Int. 2015;25:138-41.

11. Daniel J, Pynsent PB, McMinn DJ. Metal on metal resurfacing of the hip in patients under the age of 55 years with osteoarthritis. $J$ Bone Jt Surg Br. 2004;86B:177-84.

12. McBryde CW, Dehne K, Pearson AM, Treacy RB, Pynsent PB. One-or-two-stage bilateral metal-on-metal hip resurfacing arthroplasty. J Bone Jt Surg Br. 2007;89B:1144-8.

13. Woon RP, Amstutz HC. High performance of metal-on-metal bearings: a case report. J Surg Orthop Adv. 2012;21:170-5.

14. Van Der Straeten C, Grammatopoulos G, Gill HS, Calistri A, Campbell P, De Smet KA. The 2102 Otto Aufranc Award; the interpretation of metal ion levels in unilateral and bilateral hip resurfacing. Clin Orthop Relat Res. 2013;471:377-85.

15. Reito A, Lainiala O, Nieminen J, Eskelinen A. Repeated metal ion measurement in patients with bilateral metal on metal (ASR ${ }^{\mathrm{TM}}$ ) hip replacements. Orthop Traumatol Surg Res. 2016;102:167-73.

16. Matharu GS, Berryman F, Brash L, Pynsent PB, Dunlop DJ, Treacy RB. Can blood metal ion levels be used to identify patients with bilateral Birmingham Hip Resurfacings who are at risk of adverse reactions to metal debris? Bone Jt J. 2016;98:1455-62.

17. Jiang $W$, Wan $Y$, Cui $P$, Ning $X$. Intermediate-term trends in serum levels of metal ions after hip resurfacing arthroplasty. J Orthop Surg Res. 2015;10:188.

18. Pandit H, Vlychou M, Whitwell D, Crook D, Luqmani R, Ostlere S, Murray DW, Athanasou NA. Necrotic granulomatous pseudotumours in bilateral resurfacing hip arthroplasties: evidence for a type IV immune response. Virchows Arch. 2008;453:529-34.

19. Grammatopoulos G, Pandit H, Kamail A, Maggiani F, Glyn-Jones G, Gill HS, Murray DW, Athanasou NA. The correlation of wear with histological features after failed hip resurfacing arthroplasty. J Bone Jt Surg Am. 2013;95A:e81.

20. Grammatopoulos G, Munemoto M, Pollalis A, Athanasou NA. Correlation of serum metal ion levels with pathological changes of A RMD in failed metal-on-metal-hip-resurfacing arthroplasties. Arch Orthop Trauma Surg. 2017;8:1129-37.

21. Rae T. A study on the effects of particulate metals of orthopaedic interest on murine macrophages in vitro. J Bone Jt Surg Br. 1975;57B:444-50.

22. Papageorgiou I, Brown C, Schins R, et al. The effect of nano-and micron- sized particles of cobalt-chromium alloy in human fibroblasts in vitro. Biomaterials. 2007;28:2496-58.

23. Gill HS, et al. Molecular and immune toxicity of CoCr nanoparticles in MoM hip arthroplasty. Trends Mol Med. 2012;18:145-55.

24. Merritt K, Brown SA. Distribution of cobalt chromium wear and corrosion products and biologic reactions. Clin Orthop. 1996;329S:S233-43.

25. Hart AJ, Sabah SA, Sampson B, et al. Surveillance of patients with metal-on-metal hip resurfacing and total hip prosthesis; a 
prospective cohort study to investigate the relationship between blood metal ion levels and implant failure. J Bone Jt Surg Am. 2014;96A:1091-9.

26. Reito A, Moilanen T, Puolakka T, Pajamaki J, Eskelinen A. Repeated metal ion measurements in patients with high risk metalon-metal hip replacement. Int Orthop. 2014;38:1353-61.

27. Griffin WL, Fehring TK, Kudrna JC, et al. Are metal ion levels a useful trigger for surgical intervention? J Arthroplast. 2012;27:36-36

28. Germain MA, Hatton A, Williams S, Matthews JB, Stone MH, Fisher J, Ingham E. Comparison of the cytotoxicity of clinically relevant cobalt-chromium and alumina ceramic wear particles in vitro. Biomaterials. 2003;24:469-79.

29. Posada OM, Tate RJ, Grant MH. Effects of Co $\mathrm{Cr}$ metal wear debris generated from metal-on-metal hip implants and Co ions on human monocyte-like V937 cells. Toxicol in Vitro. 2015;29:271-80.

30. Slonimsky E, Kushnir T, Kadar A, Menahem A, Grundshtein A, Dekel S, Eshed I. Bilateral total hip replacement: periprosthetic pseudotumour collections are more prevalent in metal-on-metal implants composred to non metal-on-metal ones. Acta Radiol. 2016;57:463-7.
31. Madanat R, Hussey DK, Donahue GS, Potter HG, Wallace R, Bragdon CR, Muratoglu OK, Malchau $\mathrm{H}$. The symmetry of adverse local tissue reactions in patients with bilateral simultaneous and sequential ASR hip replacement. J Arthroplast. 2015;30:1794-8.

32. No authors listed. Metal-on-Metal Hip Implants - Information for Orthopaedic Surgeons regarding Patient Management following Surgery- For Health professionals. http://healthycanadians.gc.ca/ recall-alert-rappel-avis/hc-sc/2012/15835a-eng.php (date last accessed 08 August 2016)

33. Brown C, Fisher J, Ingham E. Biological effects of clinically relevant wear particles from metal-on-metal hip prostheses. Proc Inst Mech Eng Part H. 2006;220:355-69.

34. Woolley PH, Hallab NJ. Wound healing, chronic inflammation and immune responses. In: Jones LC, Greenwald S, Haggard WO, eds. Metal on metal bearing: a clinical practicum. London: Springer; 2014. p. 109-133.

35. Landgraeber S. Jager M, Jacobs JJ, Hallab NJ The pathology of orthopaedic implant failure is mediated by innate immune system cytokines. Mediat Inflamm. 2014;2014:185150. 